\title{
Factors Affect Slipping of Automobiles
}

\author{
SAYEL M. FAYYAD AND MOHANNAD O. RAWASHDEH \\ Department of Mechanical Engineering, Faculty of Engineering Technology, \\ P.O. Box 15008, Al-Balqa Applied University \\ Amman - JORDAN
}

\begin{abstract}
This article analysis the car slip phenomenon; discusses the parameters that affect the car slip. An analytical equation is constructed to relate all factors that affect the slip rate. Some relationships are expected to indicate factors that affect car skidding. It was found that the parameters that affect slip can be summarized as: the radius of curvature of the curve, the angle (slope) of the curve, the RPM of the tire, and the tire radius in addition to the nature of the road. It was found that as the normal acceleration increases, the slip rate decreases, as the RPM of the tire increases, the slip rate increases, and as the radius of the tire increases, the slip rate increases. Obviously, as the slope of the path $(\tan \theta)$ increases, the slip value decreases. Note that as the radius of curvature increases, the percentage of slip decreases, which is logical because the slip on the straight drying path is almost close to zero. It should also be noted that as the tire radius decreases, the slip rate increases.
\end{abstract}

Key-Words: - Slipping, Normal Acceleration, Radius of Curvature, Tires, Velocity, and Automobiles Dynamic

Received: January 2, 2020. Revised: May 5, 2020. Accepted: May 18, 2020. Published: June 5, 2020.

\section{Introduction}

There are many control frameworks in vehicles that can help drivers avoid accidents and threats, or reduce damage from accidents. Such frames on new vehicles regularly have an electronically monitored release mechanism (ABS), which prevents the wheels from locking during troublesome deceleration, and from time to time have electronic stability supervising the frame (ESC) or can be called (in this article) as a nonslip frame ( SPS), which balances the lateral movement of the vehicle to save you from slipping. Warning and avoidance of accidents, avoidance of rollover, side wind stabilizers and preparatory work on impending disaster by changing the position of the seats and seat belts are additional cases of monitoring vehicle safety structures. To obtain these records, advanced engines are equipped with various sensors. For an ordinary vehicle with an ESC frame, the basic estimates include the steering wheel edge, wheel deflection speed, lateral acceleration, and rotational speed around a stable pivot axis perpendicular to the body, which is called the yaw rate.
Under typical conditions, when the auto is pushed appropriately without risk of losing road grasp, the car sideslip demeanor is little, not surpassing \pm 2 degrees for the regular driver [1].

In addition, for a given pace in ordinary driving circumstances, the directing attributes indicate tight association among the direction wheel edge, yaw rate, horizontal increasing speed, and vehicle sideslip mentality. During slipping a lateral force affects the dynamics of the car, this force is proportional to the slipping angle. There is a relation between lateral forces and slipping angle which depends on the radius of curvature. During slipping a sidelong power or force influences the elements of the vehicle, this force is relative to the slipping point. And also there is a connection between sidelong powers and slipping edge which relies upon the span of the curvature.

\subsection{Road-Tire Friction}

At the point when the driver turns the controlling wheel to make a customary turn, the tires on the front hub of the vehicle become skewed with the bearing of movement, and we get a tire-slip edge. The tire-slip point is thoughtfully like the vehicle sideslip edge, then again, actually 
the pertinent edge to the reference that refers to an isolated tire opposite the body. Specifically, the tire slip edge is characterized as a point between the velocity vectors at the focal point of the tire in the Hag direction. The definition of the left front wheel is summarized in Figure 1, where $\alpha 1$ represents the tire slippage. A non-zero tire slip edge can infer the relative contrast between the speed of the road and the tire during the parallel travel of the tire.

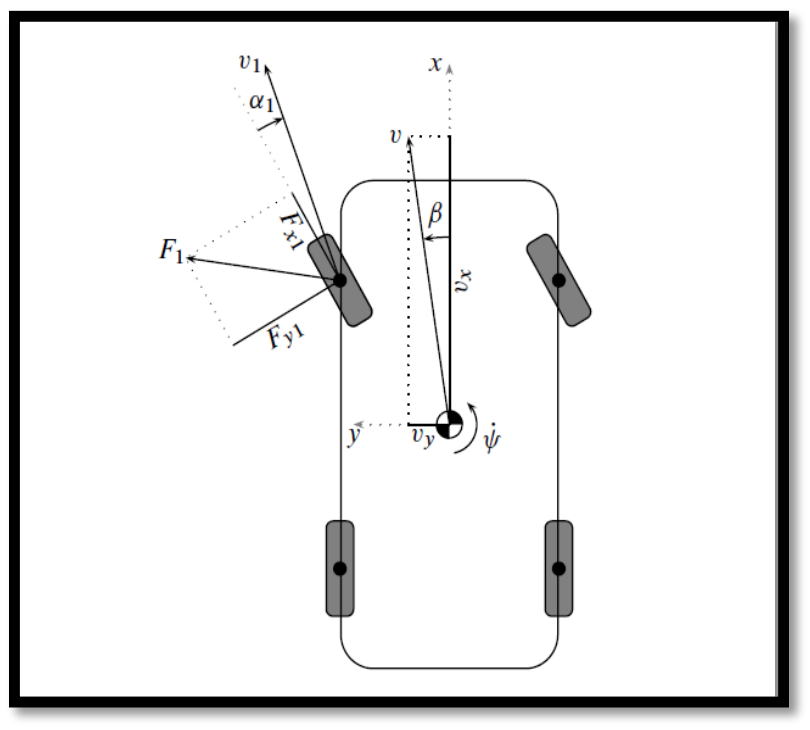

Figure 1: Vehicle speed, yaw rate, vehicle side slip angle, tire slip angle and road tire friction [1].

Many articles talked about this problem, Huemer et al. (2001); Liu et al. (2000) and Huemer et al. (2001b) related to the slip of tires with the friction of a flexible elastic material, which introduced a phenomenological contact law for a flexible track hindering driving on cement for use in a naturally visible model. The mesh factor depends on the usual weight, slip speed and temperature. The grinding coefficient itself is only an element with a typical mass and sliding speed. Temperature influences are combined using the WLF change, i.e. if the current temperature is unique in relation to the reference temperature, a proportional new sliding speed is determined for the reference temperature. The problem was discussed by Hofstetter et al. (2003), where a thermo mechanical connection is presented.
The spread of vitality during movement turns into heat, and this heat movement causes the rubber and street temperature to rise. In (Hofstetter et al., 2006) similar reconstructions of the scraped area of the track square were included. Dorsch et al. (2002) established the phenomenological law of erosion using information obtained from LAT100 probes. Displaying and estimating the transient moving contact of tires on street tracks is the subject of a multidisciplinary research project (FOR492) at the University of Hanover. One of the projects focuses on computational homogenization techniques to create contact law at a naturally visible level, in light of consequences for a tiny level. Nam et al. (2015) talked about a powerful wheel slip control framework dependent on a sliding mode controller is proposed for improving footing capacity and diminishing vitality utilization during unexpected quickening for an individual electric vehicle. Sliding mode control strategies have been utilized generally in the advancement of a vigorous wheel slip controller of customary inner ignition motor vehicles because of their application viability in nonlinear frameworks and heartiness against model vulnerabilities and unsettling influences. A down to earth slip control framework which exploits the highlights of electric engines is proposed and a calculation for vehicle speed estimation is additionally presented. The vehicle speed estimator was planned dependent on rotational wheel elements, quantifiable engine torque, and wheel speed just as rule-based rationale. The recreations and tests were completed utilizing both Car-Sim programming and a trial electric vehicle furnished with in-wheel-engines. Through field tests, footing execution and viability as far as vitality sparing were completely confirmed. Similar analyses with varieties of control factors demonstrated the adequacy and common sense of the proposed control structure. Jin et al. (2017) tended to the eyewitness structure issue for evaluating the side-slip edge and the obscure street contact coefficient, in view of estimated signals from sensors normal to present day arrangement creation autos. We plan state and parameter estimation as a non-curved improvement issue. By intertwining discrete time arrangement of the improvement and consistent combination of sensor information, our plan takes 
into consideration adequate time for finding the worldwide optima around through a lattice search. Thusly, in spite of the non-raised advancement we are confronting, our perception conspire can run progressively. We show some alluring properties of the proposed plot concerning the security and intermingling of estimation mistake. One preferred position of our eyewitness is that for the ostensible model the estimation mistake doesn't develop in any event, when the framework needs discernibleness. Reproduction shows that the proposed spectator gives exact estimation in testing situations where the vehicle executes outrageous moves and estimated signals are undermined by clamour.

\subsection{Mathematical Modelling of Slipping}

- Vehicle traffic equation when the car is traveling on any road, this may apply to the following forces shown in Figure 2.

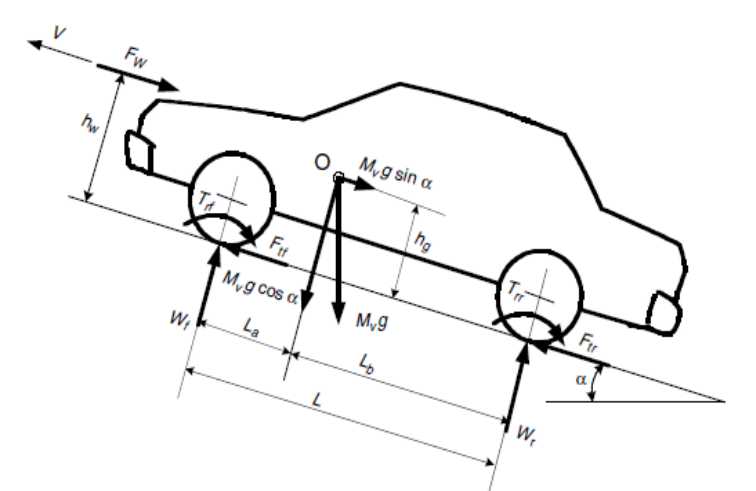

Figure 2: FBD (Free body diagram) of the automobile moving up some hill of angle $\alpha$ [1].

When applying Newton's second law, the governing equation becomes:

$M_{v} \frac{d V}{d t}=\left(F_{t f}+F_{t r}\right)-\left(F_{r f}+F_{r r}+F_{w}+F_{g}\right)$

\subsection{The Curvilinear Motion of the Car}

Each particle moves on a curve with a radius $\rho$ applied to a force called normal force, which acts on the particle and causes so-called slip. The slip percentage depends on many factors, such as (depending on [1]): car speed, $\mathrm{V}$, rolling tire radius, $r$, tire angular speed, $w$, road nature: dry, wet, snow, rainy ... etc. Tire slip can be defined as:

$$
s=\left(1-\frac{V}{r w}\right) \times 100 \%=\left(1-\frac{r_{e}}{r}\right) \times 100 \%
$$

Where $\mathrm{V}$ : is the speed of the vehicle while driving $(\mathrm{m} / \mathrm{s}), \mathrm{r}$ : is the effective radius of the tire $(\mathrm{m}), \mathrm{w}$ : is the angular speed of the tire $(\mathrm{rad} / \mathrm{s})$. But it is known from dynamics that all particle movements in a curve with a radius $(\rho)$ undergo two types of acceleration: tangential at and normal, and such that:

$a_{t}=d V / d t, \quad$ and

$a_{n}=V^{2} / \rho$

The normal acceleration component is responsible for causing slip, and the speed in equation (2) can be replaced as:

$V=\sqrt{a_{n} \rho}$

This yields to

$s=\left(1-\frac{\sqrt{a_{n} \rho}}{r \omega}\right) 100 \%$

Curvature radius of any curve can be written as:

$\rho(x)=\frac{\sqrt{\left(1+y^{\prime}(x)^{2}\right)^{3}}}{y^{\prime \prime}(x)}$

Substitute equation (5) in (4) to get

$$
s=\left(1-\frac{\sqrt{a_{n}}(1+\tan \theta)^{3 / 4}}{r \omega \sqrt{y^{\prime \prime}}}\right) 100 \%
$$

Equation (7) describes the slip rate as a function of normal acceleration and tangential acceleration, which is considered constant here, and the slip rate is also a function of the effective radius of the tire and the angular velocity of the tire. 
Calculate the tire slip error using equation (7) by differentiating $\mathrm{s}$ with respect to $\mathrm{r}$ or $\theta$, thus:

$s_{\text {error }}=\frac{\sqrt{a_{n}}(1+\tan \theta)^{3 / 4} * \omega \sqrt{y^{\prime \prime}}}{\left(r \omega \sqrt{y^{\prime \prime}}\right)^{2}} r_{\text {error }}$

While the error with respect to $\theta$ can be given as

$$
s_{\text {error }}=-0.75 \frac{\sqrt{a_{n}}(1+\tan \theta)^{-1 / 4}}{r \omega \sqrt{y^{\prime \prime}}} \sec \theta^{*} \theta_{\text {error }}
$$

\section{Results and Discussion}

It can be noted that as the normal acceleration increases, the slip rate decreases. Figure 3 shows the relationship between the percentage of slip and the normal acceleration of the car during the linear motion of the car's curve.

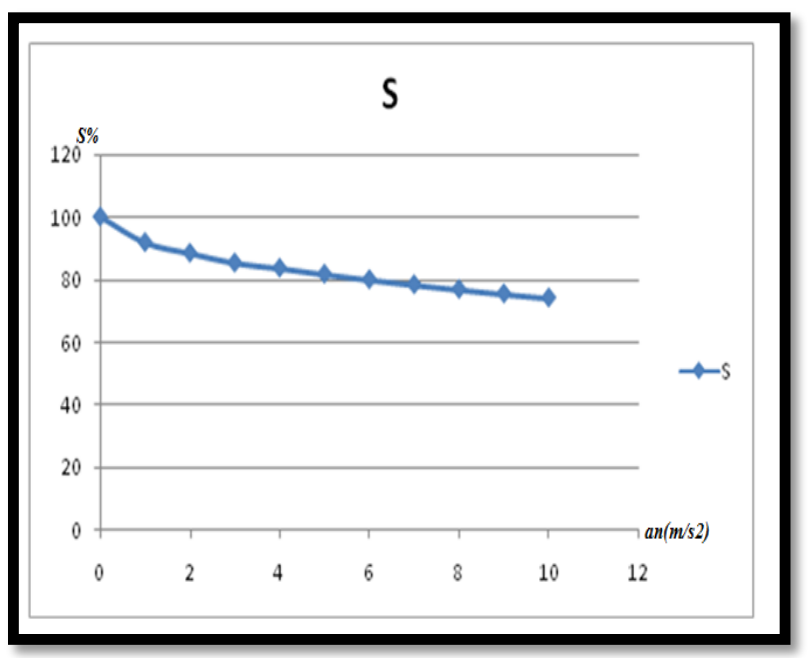

Figure 3: Slip rate and normal acceleration

Situation two: the relationship between slip rate and tire angular velocity. Fig. 4 shows the relationship between the slip rate and the tire angular velocity.

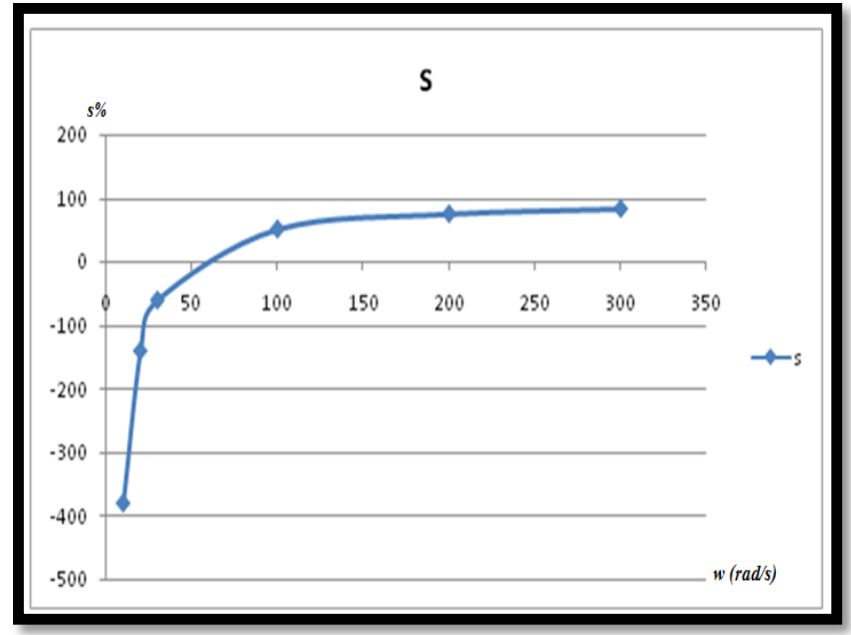

Figure 4: effect of angular speed of the tire on slipping ratio

Situation three. The relationship between the slip rate and the effective rolling radius of the tire. Figure 5 shows the relationship between slip rates as a function of tire radius. The results show that as the tire radius increases, the slip rate increases.

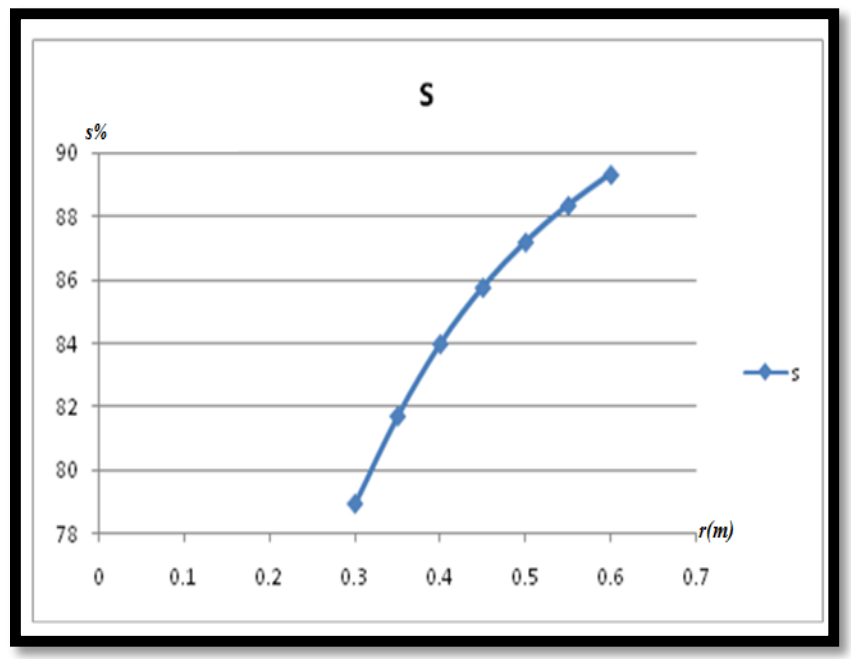

Figure 5: effect of radius of the tire on slipping rate.

Situation 4. The influence of path slope on slip rate: Figure 6 shows the effect of road gradient $(\tan \theta)$ on slip rate. Obviously, as the slope of the path $(\tan \theta)$ increases, the slip value decreases. 


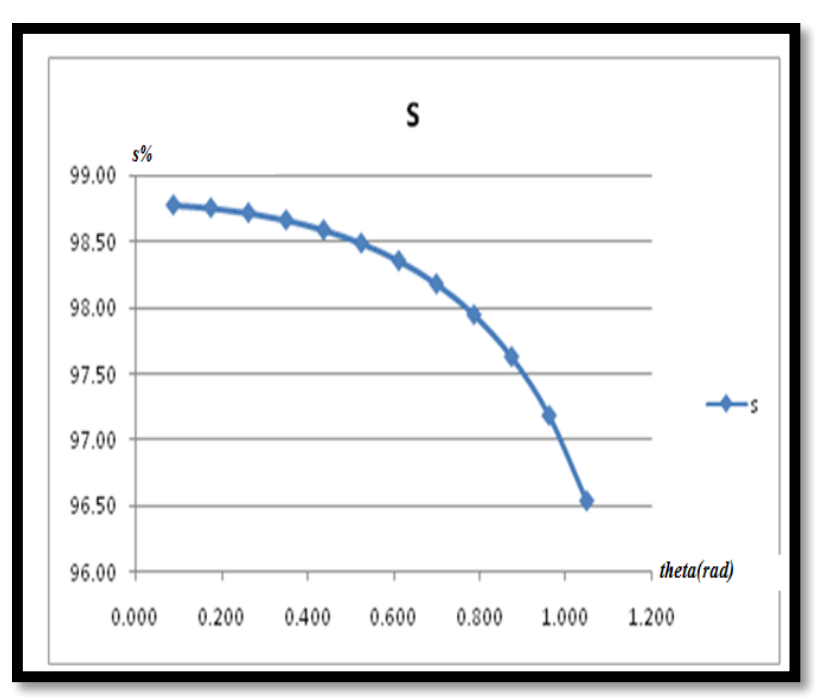

Figure 6: the effect of road slope on slipping percent.

Situation 5. The relationship between the slip rate and the radius of curvature of the path. Figure 7 shows the relationship between the percentage of slip and the radius of curvature of the path. It can be noticed that as the radius of curvature increases, the sliding percentage decreases, which is logical, and the sliding on the straight drying path is almost close to zero.

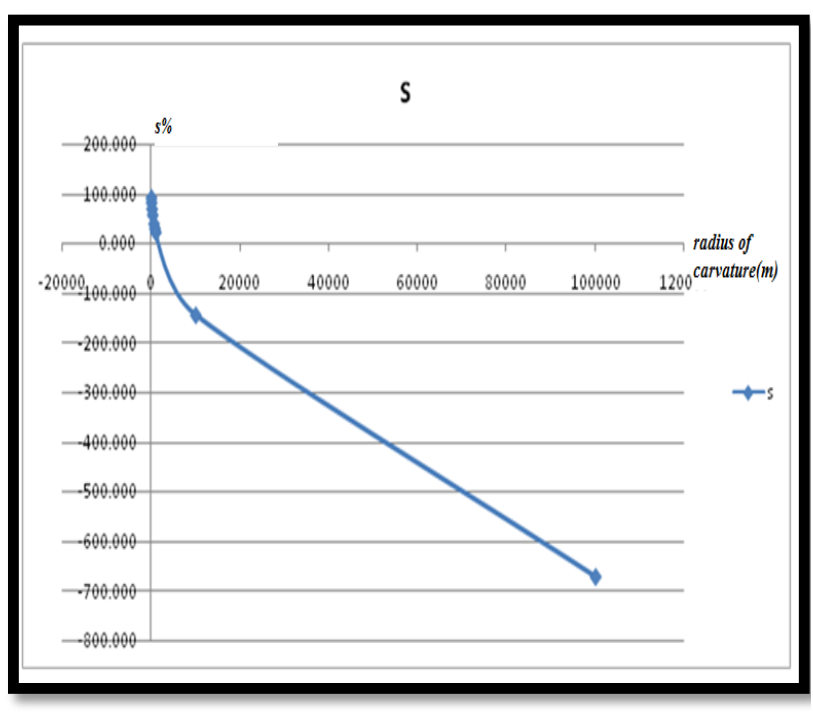

Figure 7: the radius of curvature of the path effect on slipping

Case six. The relationship between the slip rate and the rate of decrease of the tire radius $(\Delta r)$ with time. Fig. 8 shows the relationship between slip rate and tire corrosion. It can be noted that as the tire radius decreases (more corrosion), slippage increases.

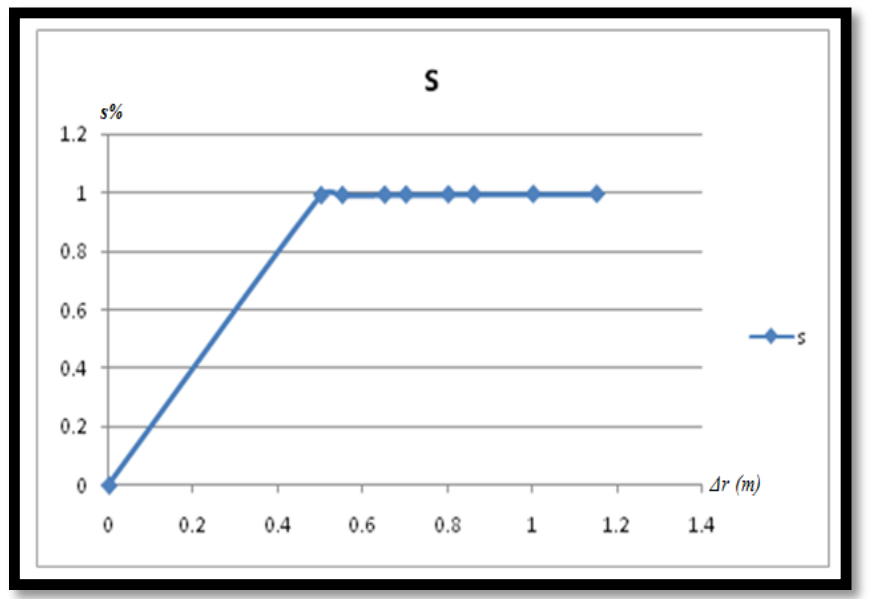

Figure 8: Tire wear effect on slipping percent

\section{Conclusions}

It was found that as the normal acceleration increases, the slip rate decreases. Similarly, as the RPM of the tire increases, the slip rate also increases. It can be noted that as the tire radius increases, the slip rate increases. Obviously, as the slope of the path $(\tan \theta)$ increases, the slip value decreases. It can also be noted that as the radius of curvature increases, the slip percentage decreases, which logically slips on a straight drying path almost close to zero. It can be noticed that as the tire radius decreases (more wear), the slip increases.

\section{References:}

[1] H.R. Muhammad, G. Yimin, E.G. Sebastien, and E. Ali, 2004, Modern Electric, Hybrid Electric, And Fuel Cell Vehicles, CRC Press.

[2]A. T. van Zanten, "Bosch ESP systems: 5 years of experience," in Proc. Automot. Dyn. Stabil. Conf., Troy, MI, 2000, paper no. 2000-011633.

[3] J. Farrelly and P. Wellstead, "Estimation of vehicle lateral velocity," in Proc. IEEE Int. Conf. Contr. Appl., Dearborn, MI, 1996, pp. 552-557. 
[4] Y. Fukada, "Slip-angle estimation for vehicle stability control," Vehicle Syst. Dyn., vol. 32, no. 4, pp. 375-388, 1999.

[5] P. J. TH. Venhovens and K. Naab, "Vehicle dynamics estimation using Kalman filters," Vehicle Syst. Dyn., vol. 32, no. 2, pp. 171-184, 1999.

[6] A. Y. Ungoren, H. Peng, and H. E. Tseng, "A study on lateral speed estimation methods," Int. J. Veh. Auton. Syst., vol. 2, no. 1/2, pp. 126-144, 2004.

[7] U. Kiencke and A. Daib, "Observation of lateral vehicle dynamics," Contr. Eng. Pract., vol. 5, no. 8, pp. 1145-1150, 1997.

[8] U. Kiencke and L. Nielsen, Automotive Control Systems: For Engine, Driveline, and Vehicle. Springer, 2000.

[9] M. Hiemer, A. von Vietinghoff, U. Kiencke, and T. Matsunaga, "Determination of the vehicle body slip angle with non-linear observer strategies," in Proc. SAE World Congress, Detroit, MI, 2005, paper no. 2005-01-0400.

[10] A. von Vietinghoff, M. Hiemer, and U. Kiencke, "Nonlinear observer design for lateral vehicle dynamics," in Proc. IFAC World Congress, Prague, Czech Republic, 2005, pp. 988-993.

[11]A. von Vietinghoff, S. Olbrich, and U. Kiencke, "Extended Kalman filter for vehicle dynamics determination based on a nonlinear model combining longitudinal and lateral dynamics," in Proc. SAE World Congress, Detroit, MI, 2007, paper no. 2007-01-0834.

[12] A. Suissa, Z. Zomotor, and F. Böttiger, "Method for determining variables characterizing vehicle handling," US Patent 5,557,520, 1994, filed Jul. 29, 1994; issued Sep. 17, 1996.

[13] L. R. Ray, "Nonlinear tire force estimation and road friction identification: Simulation and experiments," Automatica, vol. 33, no. 10, pp. 1819-1833, 1997.
[14] M. C. Best, T. J. Gordon, and P. J. Dixon, "An extended adaptive Kalman filter for realtime state estimation of vehicle handling dynamics," Vehicle Syst. Dyn., vol. 34, no. 1, pp. 57-75, 2000 .

[15] H. Lee, "Reliability indexed sensor fusion and its application to vehicle velocity estimation," J. Dyn. Syst. Meas. Contr., vol. 128, no. 2, pp. 236-243, 2006.

[16] A. Hac and M. D. Simpson, "Estimation of vehicle side slip angle and yaw rate," in Proc. SAE World Congress, Detroit, MI, 2000, paper no. 2000-01-0696.

[17] W. Klier, A. Reim, and D. Stapel, "Robust estimation of vehicle sideslip angle - an approach w/o vehicle and tire models," in Proc. SAE World Congress, Detroit, MI, 2008, paper no. 2008-010582.

[18] H. E. Tseng, "Dynamic estimation of road bank angle," Vehicle Syst. Dyn., vol. 36, no. 4, pp. 307-328, 2001.

[19] C. Sentouh, Y. Sebsadji, S. Mammar, and S. Glaser, "Road bank angle and faults estimation using unknown input proportional-integral observer," in Proc. Eur. Contr. Conf., Kos, Greece, 2007, pp. 5131-5138.

[20] J. Ryu and J. C. Gerdes, "Integrating inertial sensors with Global Positioning System (GPS) for vehicle dynamics control," J. Dyn. Syst. Meas. Contr., vol. 126, no. 2, pp. 243-254, 2004.

[21] D. M. Bevly, J. C. Gerdes, and C. Wilson, "The use of GPS based velocity measurements for measurement of sideslip and wheel slip," Vehicle Syst. Dyn., vol. 38, no. 2, pp. 127-147, 2002.

[22] D. M. Bevly, "Global Positioning System (GPS): A low-cost velocity sensor for correcting inertial sensor errors on ground vehicles," J. Dyn. Syst. Meas. Contr., vol. 126, no. 2, pp. 255-264, 2004.

[23] D. M. Bevly, J. Ryu, and J. C. Gerdes, "Integrating INS sensors with GPS 
measurements for continuous estimation of vehicle sideslip, roll, and tire cornering stiffness," IEEE Trans. Intell. Transport. Syst., vol. 7, no. 4, pp. 483-493, 2006.

[24] J. A. Farrell, Aided navigation: GPS with high rate sensors. McGraw-Hill, 2008.

[25] J.Y. Wong, Theory of Ground Vehicles, John Wiley \& Sons, New York, 1978.

[26] Bosch, Automotive Handbook, by Robert Bosch GmbH, Stuttgart, 2000.

[27] S. Mizutani, Car Electronics, Sankaido Co., Warrendale, PA, 1992.

[28] Chi Jin, Liang Shao, Cornelia Lex and Arno Eichberger (2017). Vehicle Side Slip Angle Observation with Road Friction Adaptation. Conference Paper • July 2017. https://www.researchgate.net/publication/31581 $\underline{5208}$

[29] Kanghyun Nam 1, Yoichi Hori 2 and Choonyoung Lee (2014). Wheel Slip Control for Improving Traction-Ability and Energy Efficiency of a Personal Electric Vehicle. Energies 2015, 8, 6820-6840

\section{Contribution of individual authors to the creation of a scientific article (ghostwriting policy)}

-Sayel M. Fayyad derived the mathematical model in its final state and carried out the simulation and the optimization. Also writing up the article with sharing with the second author.

-Mohannad O. Rawashdeh preparing data from real cases and apply the final derived equations on them to extract the results and conclusions.

\section{Creative Commons Attribution License 4.0 (Attribution 4.0 International, CC BY 4.0)}

This article is published under the terms of the Creative Commons Attribution License 4.0

https://creativecommons.org/licenses/by/4.0/deed.en_US 